\title{
Medullary involvement in neurosyphilis: a report of 12 cases and a review of the literature
}

\author{
Hafida Elmouden ${ }^{1} \cdot$ Nisserine Louhab ${ }^{1} \cdot$ Najib Kissani $^{1}$
}

Received: 4 October 2018 / Revised: 11 April 2019 / Accepted: 11 April 2019

(c) International Spinal Cord Society 2019

\begin{abstract}
Study design Retrospective case series.

Objectives To describe the epidemiological, clinical, MRI and therapeutic features and the outcomes of patients with syphilitic myelitis in a third-level hospital in Marrakesh in southern Morocco.

Setting The Neurology Department, University Hospital Mohamed VI Marrakesh, Morocco.

Methods Twelve charts of persons with syphilitic myelitis over a period of 17 years were reviewed to determine demographics, presenting symptoms, clinical and radiological findings, biological features, treatment received and outcomes. Results There were 120 reports of neurosyphilis. Twelve patients (10\%) had syphilitic myelitis. Eleven patients (92\%) were male with mean age of 44 at presentation. Tabes dorsalis was the most common clinical form. Cerebrospinal fluid analysis showed lymphocytic meningitis in nine patients $(75 \%)$. Spine MRI was abnormal in four patients (33\%). All patients were treated with 30 million units of aqueous penicillin G IV per day for 10 days, every 3 months. In follow-up, two patients $(17 \%)$ with clinical syphilitic meningomyelitis improved significantly, eight patients $(66 \%)$ with tabes dorsalis and subacute transverse myelitis showed partial improvement but clinical status was stationary for two patients (17\%) with Erb paraplegia. Conclusions All patients with myelopathy should undergo syphilitic serology because of nonspecific manifestations and curability of this disease.
\end{abstract}

\section{Introduction}

Neurosyphilis (NS) is a central nervous system infection caused by Treponema pallidum. NS can develop in the over $10 \%$ of patients that are inadequately treated or untreated [1]. Since the advent of penicillin therapy, symptomatic neurosyphilis is extremely rare; however, since 1980 and the epidemic of HIV, cases of syphilis have significantly increased worldwide. Recently, syphilis outbreaks have been reported in homosexual men [2, 3].

Neurosyphilis is characterized by clinical polymorphism and can be manifested as meningitis, parenchymatous or meningovascular involvement [4]; however, atypical or oligosymptomatic aspects have become more frequent [5]. Medullary involvement is rare in neurosyphilis and

Hafida Elmouden

elmouden.hafida@gmail.com

1 Neurology Department, University Hospital Mohamed VI Marrakesh, Marrakesh, Morocco infrequently causes myelopathic syndromes. Diagnosing syphilitic myelitis is difficult because it mimics other common conditions such as spinal cord infarction, idiopathic transverse myelitis and acute disseminated encephalomyelitis $[6,7]$.

Syphilitic myelitis, as a potentially curable disease entity of NS, must be included in the differential diagnosis of myelopathy and strong suspicion and early treatment is essential to lessen sequelae [7]. Medullary involvement in neurosyphilis has not been well-documented and few cases have been reported in the literature; thus, we reviewed our patient population to document their clinical course.

\section{Material and methods}

We reviewed the medical records of 12 patients consecutively followed for syphilitic myelitis between January 2000 and December 2017.

Inclusion criteria were positive syphilitic serology (VDRL and TPHA) in cerebrospinal fluid (CSF) in patients with myelopathy and positive syphilitic serology in the 
blood. Records were analyzed to determine demographics, presenting symptoms, clinical and radiological findings, biological features, treatment received and outcomes.

The authors defined the recovery as follows:

Significant recovery: the ability to walk without assistance returns with complete disappearance of sphincter disturbances.

Partial recovery: the ability to walk is only possible with help or support and the patient retains some sphincter disturbances.

Stationary: there is a complete absence of any improvement in motor, sensory or sphincter disturbances.

\section{Results}

Demographic data, clinical features, investigations, treatment and outcome are summed up in Tables 1 and 2.

\section{Demographic profile}

Eleven individuals (92\%) were male with a mean age of 44 years (33-57). Four patients had a history of risky sexual behavior (unprotected heterosexual intercourse). Two had a history of untreated genital ulcer (16\%), and the median duration of illness after presenting ulceration was 20 years (8-33). Two cases of inadequately treated primary syphilis were noted while previous drug abuse was found in seven patients. No sexually transmitted infections such as hepatitis $\mathrm{B}$ and $\mathrm{C}$, herpes, HIV and Neisseria gonorrhoeae were reported. Mean follow-up was 20 months (range 15-30 months).

\section{Clinical features}

Ten individuals had chronic myelopathy and two had subacute transverse myelitis. Tabes dorsalis was the most common clinical form of chronic myelopathy, being present in six patients. Syphilitic meningomyelitis was present in four individuals while two had a very slow progression of paralysis over many years known as Erb paraplegia.

\section{Investigations}

CSF analysis showed lymphocytic meningitis in nine individuals: Cell count was $20-690$ cells $/ \mathrm{mm}^{3}$ (average 252, 44 cells $/ \mathrm{mm}^{3}$ ) and protein $0,3-1,64 \mathrm{~g} / 1$ (average $0.8 \mathrm{~g} / \mathrm{l}$ ). Two CSF analyses were normal. One case had albuminocytologic dissociation with cell counts $<3$ cells $/ \mathrm{mm}^{3}$ and hyperproteinurachia at 2,97g/l. CSF venereal disease research laboratory (VDRL) was reactive while HIV serology was negative in all cases.

\section{Neuroimaging findings}

Magnetic resonance imaging (MRI) of the spine was abnormal in four individuals (Figs. 1-3). Syringomyelia was present in one case and spinal cord atrophy in two cases. All cases had hyperintense signals on T2 sequences in the spinal cord.

\section{Treatment and outcome}

All patients were treated with 30 million units of aqueous penicillin G IV per day for 10 days, every 3 months. Patients received an average of four courses of penicillin $G$ for their treatment (range 3-6 courses). On a follow-up of patients for an average of 21 months (range 15-30), it was found that two patients (17\%) with clinical syphilitic meningomyelitis improved significantly, eight patients $(66 \%)$ with tabes dorsalis and subacute transverse myelitis showed partial improvement but clinical status was stationary for two patients (17\%) with Erb paraplegia.

Repeated CSF analysis performed at the end of the third course of treatment showed partial improvement of lymphocytic pleocytosis, regression of the protein level in all patients, negative CSF-VDRL in seven cases, while the other five had negative serology 6 months later. Spine MRI was repeated in one patient (case 7) and showed that the hyperintensity had disappeared with generalized dorsal spinal cord atrophy.

\section{Discussion}

Neurosyphilis caused by the spirochete Treponema pallidum is an endemic infection of the central nervous system. It is an important sexually transmitted disease [1]. Neurosyphilis is generally known as a late manifestation of syphilis, but neurological involvement can also be seen in early syphilis [8], and T. pallidum can be found in the CSF of patients with primary syphilis [9]. The incidence of syphilis has increased in person with a history of immunosuppression and same sex. Clinical and epidemiological data have changed considerably compared to the preantibiotic era [10]. Yahyaoui et al. [11] reported a series of 201 individuals between 1986 and 1997 and Rafai et al. [12] reported on 55 cases over a period of 12 years. The prevalence of NS in sub-Saharan Africa is not negligible. In Guinea, Cisse et al. [13] reported 82 cases between 1986 and 1991 and 28 cases between 1992 and 2000 and in South Africa, Timmermans and Carr [10] collected 161 cases over a period of 10 years. In the United States, the number of cases of late syphilis has been slowly increasing every year since 1993 (17.2\% per year) [14] while a northern Indian study reported 25 cases of NS over 13 years [15]. 


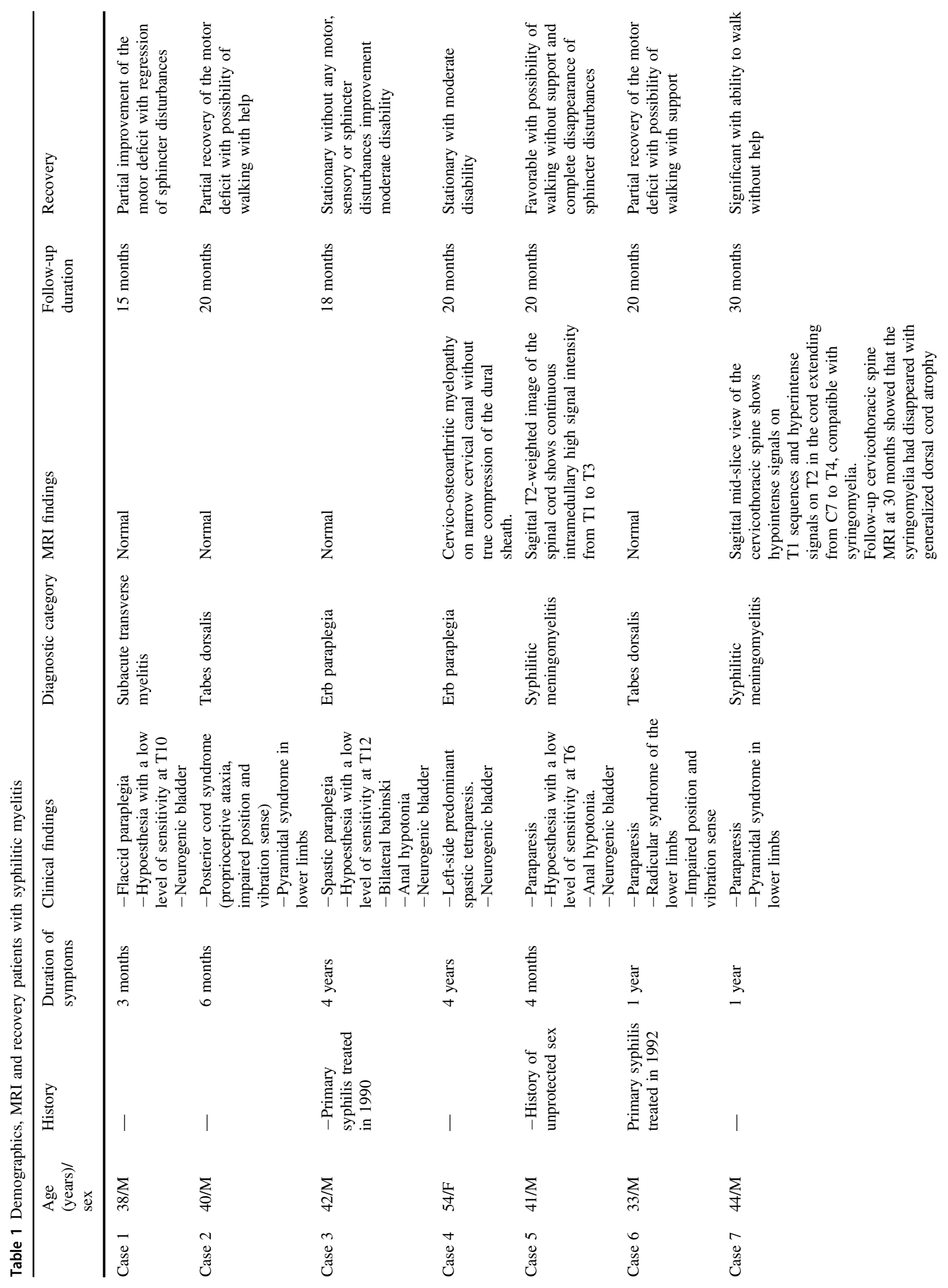




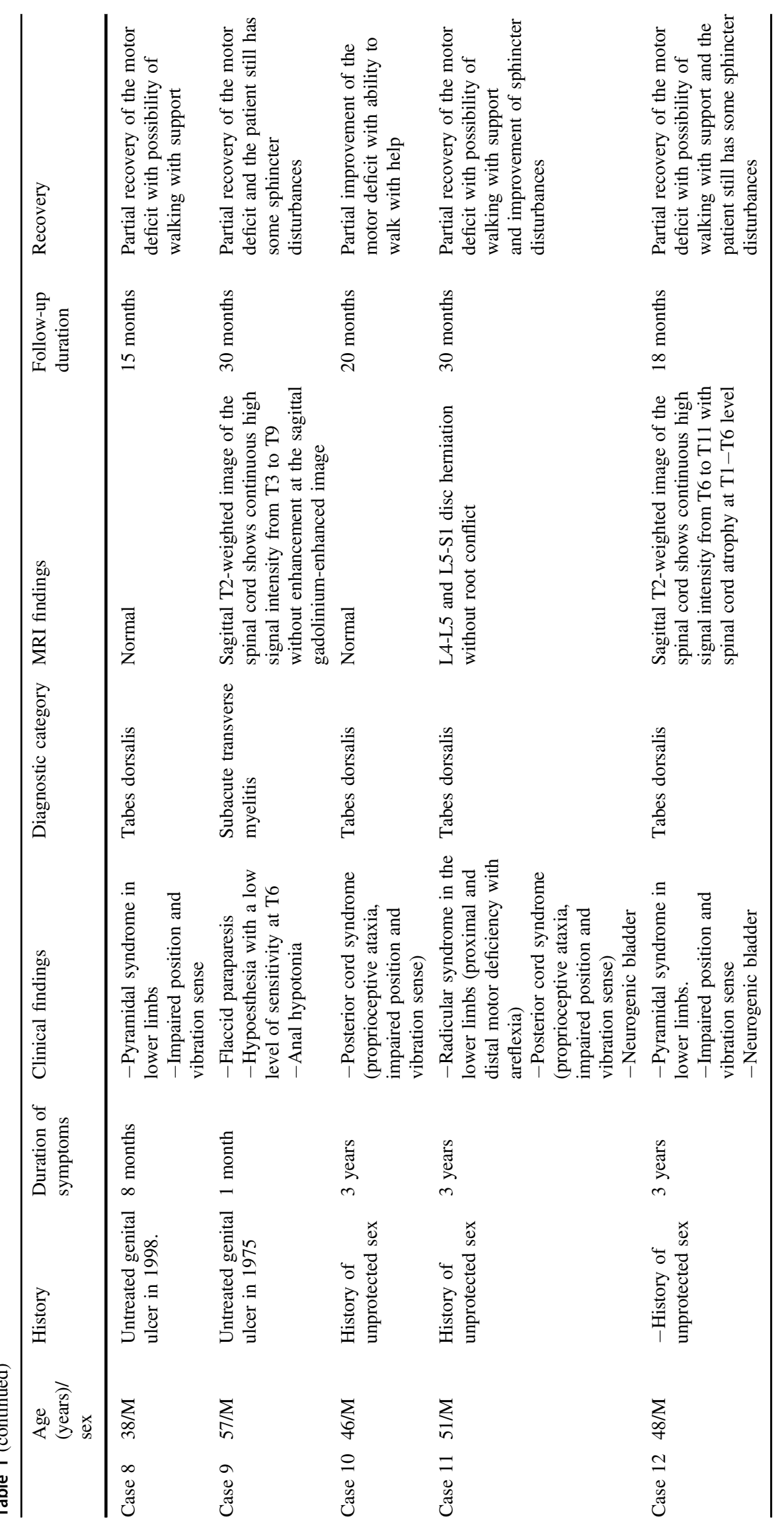


Table 2 CFS profile of patients with syphilitic myelitis
CSF analysis

\begin{tabular}{|c|c|c|}
\hline & CSF analysis & $\begin{array}{l}\text { Repeat CSF analysis at the end of the third cure } \\
\text { of Peni G }\end{array}$ \\
\hline Case 1 & $\begin{array}{l}\text {-Cell counts }<3 \text { cells } / \mathrm{mm}^{3} \\
\text {-Albuminorachia: } 0.43 \mathrm{~g} \\
\text {-VDRL1/16, TPHA: }+++\end{array}$ & $\begin{array}{l}\text {-Cell counts }<3 \text { cells } / \mathrm{mm}^{3} \\
\text { - Albuminorachia: } 0.23 \mathrm{~g} \\
\text { - VDRL - }\end{array}$ \\
\hline Case 2 & $\begin{array}{l}\text { - Lymphocytic meningitis: } \\
\text { (cell counts: } 350 \text { lymphocytes } / \mathrm{mm}^{3} \text {, } \\
\text { hyperalbuminorachia at } 0.77 \mathrm{~g} / 1 \text { ) } \\
\text {-VDRL } 1 / 32 \text {, TPHA } 1 / 5120\end{array}$ & $\begin{array}{l}\text { - Regression of the lymphocytic meningitis (cell } \\
\text { counts }: 150 \text { lymphocytes } / \mathrm{mm}^{3}, \\
\text { hyperalbuminorachia at } 0.5 \mathrm{~g} / \mathrm{l} \text { ) } \\
\text {-(VDRL: } 1 / 2 \text {, TPHA } 1 / 260 \text { ) }\end{array}$ \\
\hline Case 3 & $\begin{array}{l}\text { - Lymphocytic meningitis: } \\
\text { (cell counts } 128 \text { lymphocytes } / \mathrm{mm}^{3} \\
\text { Hyperalbuminorachia at } 0.90 \mathrm{~g} / \mathrm{l} \text { ) } \\
\text { - VDRL } 1 / 2 \text {, TPHA } 1 / 530\end{array}$ & $\begin{array}{l}\text {-Cell counts }<3 \text { cells } / \mathrm{mm}^{3} \\
\text { - Albuminorachia: } 0.22 \mathrm{~g} \\
\text {-VDRL - }\end{array}$ \\
\hline Case 4 & $\begin{array}{l}\text {-Cell counts }<3 \text { cells } / \mathrm{mm}^{3} \\
\text {-Albuminorachia: } 0.22 \mathrm{~g} / 1 \\
\text {-VDRL: } 1 / 2, \text { TPHA: } 1 / 650\end{array}$ & $\begin{array}{l}\text {-Cell counts }<3 \text { cells } / \mathrm{mm}^{3} \\
\text {-Albuminorachia: } 0.20 \mathrm{~g} / \mathrm{l} \\
\text {-VDRL - }\end{array}$ \\
\hline Case 5 & $\begin{array}{l}\text {-Lymphocytic meningitis: } \\
\text { (Cell counts: } 200 \text { lymphocytes } / \mathrm{mm}^{3} \text {, } \\
\text { hyperalbuminorachia at } 1.36 \mathrm{~g} / \mathrm{l}) \\
\text {-VDRL } 1 / 4, \text { TPHA } 1 / 2560\end{array}$ & $\begin{array}{l}\text { - Regression of the lymphocytic meningitis } \\
\text { (Cell counts: } 80 \text { lymphocytes } / \mathrm{mm}^{3} \text {, } \\
\text { hyperalbuminorachia at } 0.80 \mathrm{~g} / \mathrm{l}) \\
\text {-VDRL - }\end{array}$ \\
\hline Case 6 & $\begin{array}{l}\text {-Lymphocytic meningitis (cell counts: } 98 \% \\
\text { of lymphocyte with hyperproteinurachia at } \\
0.5 \mathrm{~g} / \mathrm{l} \text { ). } \\
\text {-VDRL: } 1 / 8, \text { TPHA: } 1 / 2960\end{array}$ & $\begin{array}{l}\text { - Regression of the lymphocytic meningitis (cell } \\
\text { counts: } 20 \% \text { of lymphocyte, proteinurachia at } \\
0.4 \text { g/l). } \\
\text {-(VDRL: } 1 / 2 \text {, TPHA } 1 / 640 \text { ). }\end{array}$ \\
\hline Case 7 & $\begin{array}{l}\text {-Lymphocytic meningitis: } \\
\text { (Cell counts: } 24 \text { lymphocytes } / \mathrm{mm}^{3} \text {, } \\
\text { hyperalbuminorachia } 0.81 \mathrm{~g} / \mathrm{l}) \\
\text {-VDRL 1/4,TPHA } 1 / 2560\end{array}$ & $\begin{array}{l}\text {-Cell counts }<3 \text { cells } / \mathrm{mm}^{3} \\
\text {-Albuminorachia: } 0.18 \mathrm{~g} \\
\text {-VDRL - }\end{array}$ \\
\hline Case 8 & $\begin{array}{l}\text {-Lymphocytic meningitis: } \\
\text { (Cell counts: } 20 \text { lymphocytes } / \mathrm{mm}^{3} \text {, } \\
\text { hyperalbuminorachia at } 0.60 \mathrm{~g} / \mathrm{l}) \\
\text {-VDRL } 1 / 4, \text { TPHA } 1 / 640\end{array}$ & $\begin{array}{l}\text {-Cell counts }<3 \text { cells } / \mathrm{mm}^{3} \\
\text { - Albuminorachia: } 0.28 \mathrm{~g} \\
\text {-VDRL - }\end{array}$ \\
\hline Case 9 & $\begin{array}{l}\text {-Lymphocytic meningitis: } \\
\text { (Cell counts } 320 \text { lymphocytes } / \mathrm{mm}^{3} \text {, } \\
\text { hyperalbuminorachia at } 0.90 \mathrm{~g} / \mathrm{l} \text { ) } \\
\text {-VDRL } 1 / 16 \text {, TPHA } 1 / 2560\end{array}$ & $\begin{array}{l}\text {-Regression of the lymphocytic meningitis ( } 160 \\
\text { lymphocytes } / \mathrm{mm}^{3} \text {, normoproteinorachia at } \\
0.28 \mathrm{~g} / \mathrm{l}) \\
\text {-(VDRL } 1 / 4 \text {, TPHA } 1 / 1280)\end{array}$ \\
\hline Case 10 & $\begin{array}{l}\text {-Lymphocytic meningitis: } \\
\text { (Cell counts } 690 \text { lymphocytes } / \mathrm{mm}^{3} \text {, } \\
\text { hyperalbuminorachia at } 0.67 \mathrm{~g} / \mathrm{l} \text { ) } \\
\text {-VDRL: } 1 / 64 \text {, TPHA: } 1 / 10240\end{array}$ & $\begin{array}{l}\text {-Regression of the lymphocytic meningitis ( } 560 \\
\text { lymphocytes } / \mathrm{mm}^{3} \text {, normoalbuminorachia at } \\
0.30 \mathrm{~g} / \mathrm{l}) \text {. } \\
\text {-(VDRL: } 1 / 8 \text {, TPHA } 1 / 1280 \text { ) }\end{array}$ \\
\hline Case 11 & $\begin{array}{l}\text {-Lymphocytic meningitis: (Cell counts } 310 \\
\text { lymphocytes/mm }{ }^{3} \text {, hyperalbuminorachia at } \\
0.71 \mathrm{~g} / \mathrm{l}) \text {. } \\
\text {-VDRL: } 1 / 16 \text {; TPHA: } 1 / 5120 \text {. }\end{array}$ & $\begin{array}{l}\text { - Regression of lymphocytic meningitis: (Cell } \\
\text { counts } 110 \text { lymphocytes } / \mathrm{mm}^{3} \\
\text { hyperalbuminorachia at } 0.5 \mathrm{~g} / \mathrm{l}) \\
\text {-(VDRL: } 1 / 2 \text {, TPHA } 1 / 2560 \text { ) }\end{array}$ \\
\hline Case 12 & $\begin{array}{l}\text { - Cell counts }<3 \text { cells } / \mathrm{mm}^{3} \\
\text { - Hyperproteinorachia: } 2.97 \mathrm{~g} / 1 \\
\text {-VDRL 1/4; TPHA } 1 / 2560\end{array}$ & $\begin{array}{l}\text { Cell counts }<3 \text { cells } / \mathrm{mm}^{3} \\
\text {-Albuminorachia: } 0.4 \mathrm{~g} \\
\text {-VDRL - }\end{array}$ \\
\hline
\end{tabular}

Clinical forms of NS are variable and generally divided into five major entities: asymptomatic, parenchymatous, meningeal, meningovascular, and gummatous. Clinical aspects are usually nonspecific and can be observed during the evolution of the disease. Several forms can be seen on the same patient [10].

Treponema pallidum infection can affect different parts of the central nervous system (the meninges, the brain, the brainstem, the spinal cord, the nerve roots, but also the cerebral and spinal blood vessels), so the neurosyphilis can present in various forms making the diagnosis difficult [16]. Thirty percent of patients with $T$. pallidum have CSF abnormalities indicative of an invasion of the central nervous system by the body, but only a portion of these have symptomatic neurosyphilis [16]. The concomitant presence of immunosuppressive agents or conditions such as HIV/ AIDS may alter the characteristics of neurosyphilis [16].

Only a few cases of nontabetic syphilis affecting the spinal cord are described in the literature [17]. Pathophysiologically, syphilitic myelitis has not only been associated 
Fig. 1 a Sagittal T2-weighted image of the spinal cord shows continuous high signal intensity from $\mathrm{T} 3$ to $\mathrm{T} 9$ without enhancement at the T1-weighted axial gadolinium-enhanced image $(\mathbf{b}, \mathbf{c})$
Fig. 2 a Sagittal T2-weighted image of the spinal cord shows spinal cord atrophy at $\mathrm{T} 1-\mathrm{T} 6$ level with continuous high signal intensity from T6 to T11 (b). c, d Axial T2-weighted image at T7/T8 level
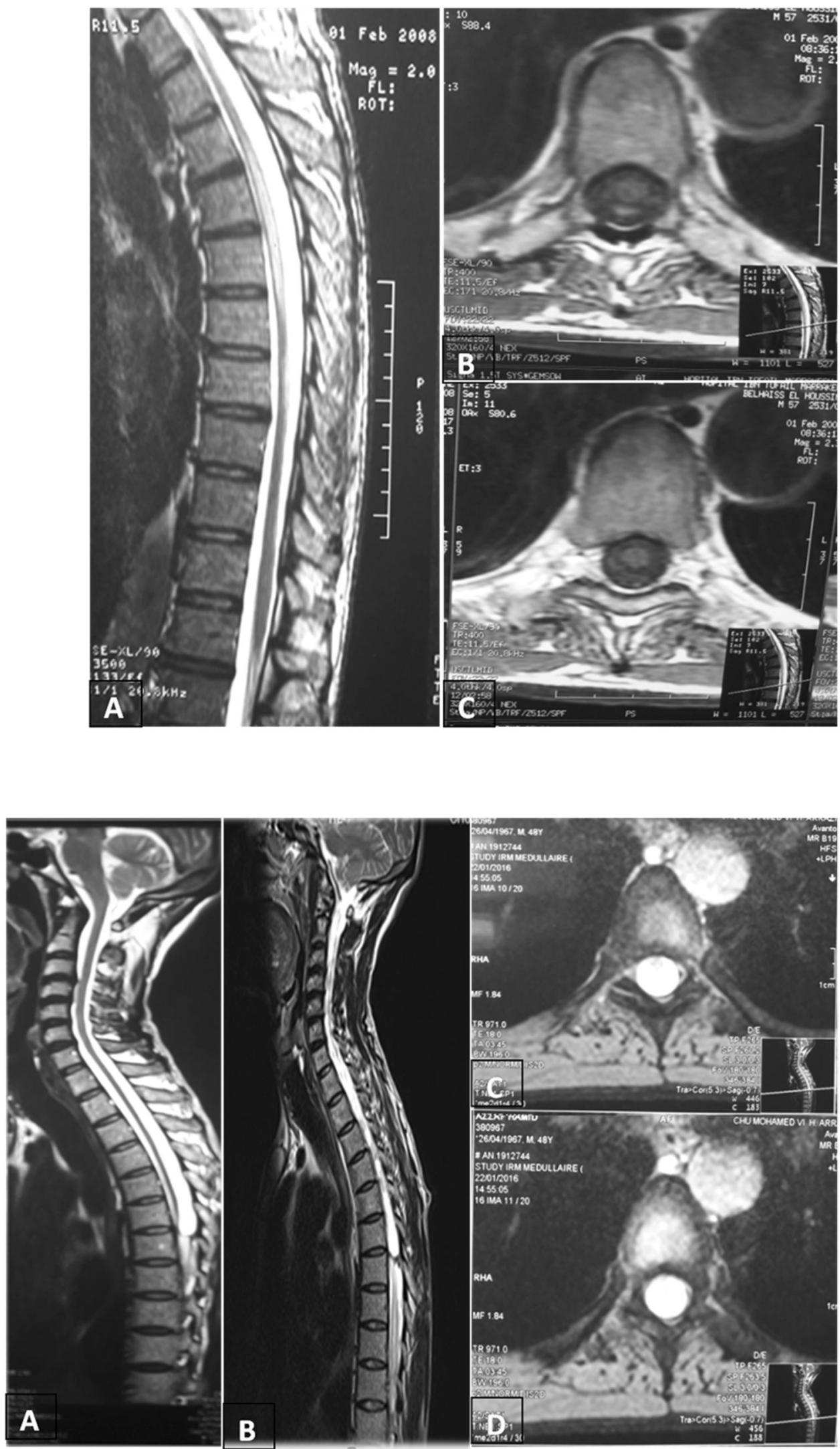
Fig. 3 a Sagittal image of the thoracic spinal cord shows hypointense signals on T1 sequence. b Hyperintense signals on $\mathrm{T} 2$ in the cord extending from $\mathrm{C} 7$ to $\mathrm{T} 4$, compatible with syringomyelia. c, d Axial view at the level of T3 shows hyperintense signals on $\mathrm{T} 2$ corresponding to a fluidfilled central cavity. e, f Followup cervicothoracic spine MRI at 30 months showed that the intramedullary high intensity areas on T2-weighted images disappeared with generalized dorsal cord atrophy

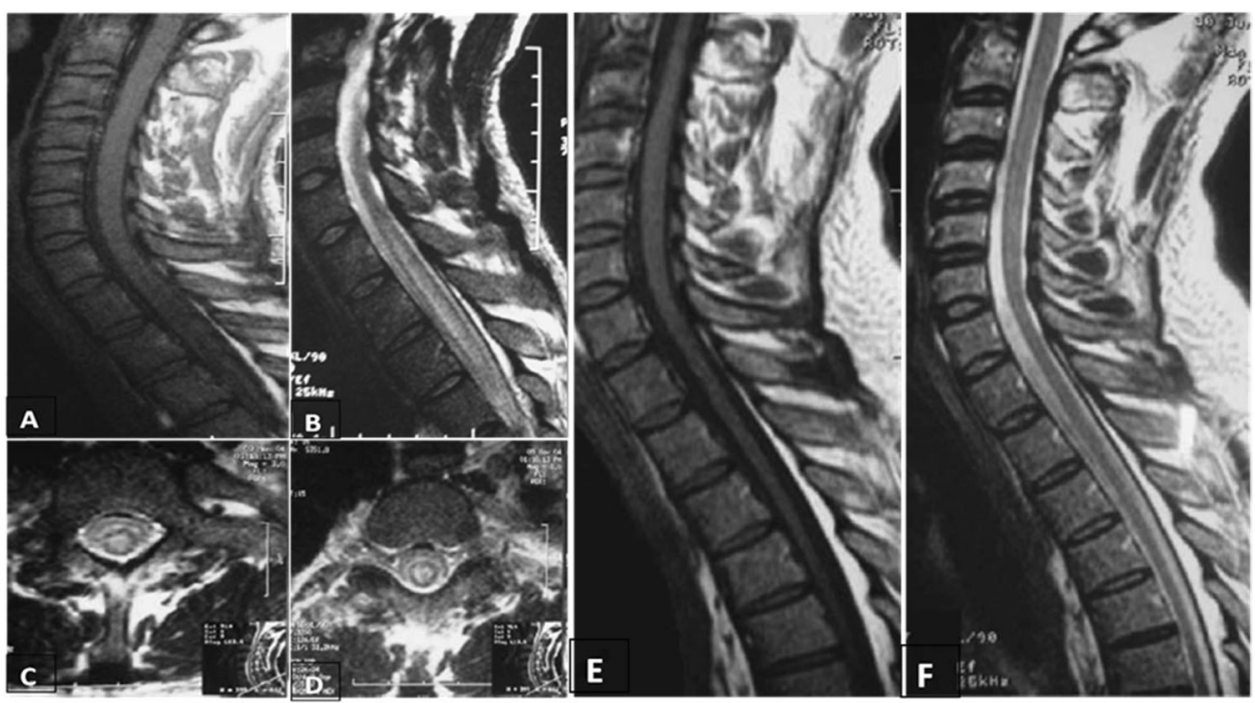

with meningomyelitis, cord atrophy or meningovascular disease, but also with compression of the spinal cord by gummae or syphilitic osteitis. Direct contamination of the marrow by the bacterium is rare [6].

Tabes dorsalis is the most well-known form of parenchymatous neurosyphilis, occurring in six of our patients. Its incidence has significantly decreased in the postantibiotic era with a relative increase in the incidence of meningovascular forms [18]. Tabes dorsalis usually occurs 15-30 years after the primary infection presents with impaired position and vibration sense, subacute to chronic sensory ataxia, and lancinating pains. Throbbing or lightning-like pain affects the legs and abdomen. Physical examination reveals hyperreflexia, pupillary abnormalities and Argyll Robertson pupils: abolition of the photomotor reflex (contraction of the pupils in the light), with preserved contraction on accommodation. Gait is ataxic and often ulcers of the feet and Charcot joints can be present [16]. Syphilitic meningomyelitis was present in four of our patients. It is described as progressively worsening paraplegia with variable sensory and sphincter disturbances and abolition of superficial abdominal reflexes [16].

Two of our patients were diagnosed with Erb's paraplegia defined as an attack of the lateral column with a degeneration of pyramidal tracts. It is a variant of meningomyelitis characterized by spasmodic paraparesis that worsens progressively and is associated with urge incontinence. The evolution is slowly progressive to a bedridden state in 10-15 years [19]. Two final cases had syphilitic transverse myelitis with sudden onset of paraplegia and loss of sensation [16].

Diagnosis of syphilitic myelitis is problematic as it mimics other causes of myelopathy. Establishing the diagnosis of neurosyphilis requires CSF analysis. The CSF cell count (usually lymphocytes) are increased, protein concentration is raised and glucose reduced or normal [20]. In our series, CSF analysis showed lymphocytic meningitis in nine patients and ten individuals had hyperalbuminorachia and normoglycorachia. The VDRL and rapid plasma reagin (RPR) tests are more sensitive in the early stages of the disease but become negative later in the majority of cases [21]. The CSF VDRL test is very specific for active NS, but it has low sensitivity. The diagnosis of NS is confirmed by positive CSF VDRL. If CSF VDRL is negative, CSF fluorescent treponemal antibody absorption (FTA) testing is used to establish the diagnosis because it is highly sensitive; and experts believe that the diagnosis of NS can be excluded if FTA-abs test on the CSF is negative [20, 22]. Treponema pallidum haemagglutination test [23] and molecular tests including PCR [24] are also assays used to diagnose neurosyphilis; and they are generally characterized by their high specificity and sensitivity.

MRI of the spine was performed in all our patients and was abnormal in four. Few reports in the literature have described the MRI abnormalities in syphilitic myelitis. The first descriptions of MRI abnormalities in syphilitic myelitis reported by Tashiro et al. [25] in 1987 were short-segment with high signal intensity in the thoracic cord on T2-weighted images and abnormal peripheral enhancement. In case 5, the spinal MRI showed similar appearance with continuous intramedullary high signal intensity from $\mathrm{T} 1$ to $\mathrm{T} 3$. The classic appearance of syphilitic myelitis is abnormal enhancement in the superficial parts of spinal cord parenchyma (candle guttering appearance), low signal intensity on T2-weighted imaging and high intensity on gadoliniumenhanced T1-weighted imaging (flip-flop sign) [26].

High-signal lesions of the spinal cord parenchyma extending confined to the central portion and extending over multiple levels on T2-weighted imaging and abnormal enhancement on gadolinium-enhanced T1-weighted images have been described [7]. This radiological aspect was noted in two individuals in our series having an extensive 
hypersignal exceeding three levels on T2-weighted imaging (Figs. 1 and 2). The difference in our two cases was the absence of contrast enhancement after gadolinium injection.

The literature indicates that intramedullary high intensity areas on T2-weighted images and gadolinium-enhancement on T1-weighted images disappear after antibiotic therapy and prednisolone [25, 27] and this was seen in case 7 (Fig. 3). Additionally, this individual had generalized dorsal cord atrophy on follow-up MRI 2.5 years post penicillin therapy been previously observed at advanced stages of the post disease [28]. Moreover, case 12 (Fig. 2) was seen after 3 years of disease evolution and had medullary atrophy on his first spine MRI.

Syphilitic spinal meningitis, as a cause of syringomyelia, has rarely been described in the literature; and only a few cases have been reported [29]. This rare form of syphilitic myelitis was found in case 7 (Fig. 3) as syrinx caused by syphilitic spinal meningitis due to the improvement of symptoms, disappearance of the syringomyelia cavity at the spinal MRI after penicillin treatment, and the absence of any other causes of syringomyelia, particularly basal intracranial arachnoiditis and cerebellar octopia.

We note radiologic normality of medullary MRI in 8 of 12 cases despite the presence of clinical symptoms of SCI; thus we conclude that syphilitic myelitis is not always accompanied by changes in spine MRI. The medullary abnormalities found in four cases of the series and previous cases reported in the literature were also localized at the level of the thoracic marrow which brings into question whether this is a simple coincidence or there is a physiopathological explanation for this location in the cord.

\section{Conclusion}

Syphilitic myelitis has no specific clinical or imaging findings. Only the practice of serologic testing for syphilis in all patients with myelopathy can diagnose this potentially treatable disease.

\section{Compliance with ethical standards}

Conflict of interest The authors declare that they have no conflict of interest.

Publisher's note: Springer Nature remains neutral with regard to jurisdictional claims in published maps and institutional affiliations.

\section{References}

1. Conde-Sendma MA, Amela-Perisa R, Aladro-Benito Y, Maroto AA. Current clinical spectrum of neurosyphilis in immunocompetent patients. Eur Neurol. 2004;52:29-35.
2. Hook EW 3rd, Marra CM. Acquired syphilis in adults. N Engl J Med. 1992;326:1060-9.

3. Fenton KA, Breban R, Vardavas R, Okano JT, Martin T, Aral S, et al. Infectious syphilis in high-income settings in the 21 st century. Lancet Infect Dis. 2008;8:244-53.

4. Kayal AK, Goswami M, Das M, Paul B. Clinical spectrum of neurosyphilis in North East India. Neurol India. 2011;59:344-50.

5. Burke JM, Schaberg DR. Neurosyphilis in the antibiotic era. Neurol. 1985;35:1368-71.

6. Chilver-Stainer L, Fischer U, Hauf M, Fux CA, Sturzenegger M. Syphilitic myelitis: rare, nonspecific, but treatable. Neurology. 2009;72:673-5.

7. Tsui EY, Ng SH, Chow L, Lai KF, Fong D, Chan JH. Syphilitic myelitis with diffuse spinal cord abnormality on MR imaging. Eur Radiol. 2002;12:2973-6.

8. Golden MR, Marra CM, Holmes KK. Update on syphilis: resurgence of an old problem. JAMA. 2003;290:1510-4.

9. Lukehart SA, Hook EW, Baker-Zander SA, Collier AC, Critchlow $\mathrm{CW}$, Handsfield HH. Invasion of the central nervous system by Treponema pallidum: implications for diagnosis and treatment. Ann Intern Med. 1988;109:855-62.

10. Timmermans M, Carr J. Neurosyphilis in the modern era. J Neurol Neurosurg Psychiatry. 2004;75:1727-30.

11. Yahyaoui M, Serragui S, Regragui W, Errguig L, Mouti O, Benomar A. et al. Epidemiological and clinical aspects of neurosyphilis in Morocco. East Mediterr Health J. 2005;11:3

12. Rafai M, Oumari S, Benmansour Y, Ibnmoufti R, Ibnkhribchia R, Boulaajaj F. Neurosyphilis: clinical aspects, CSF, radiological finding, treatment and outcome: a Moroccan series. Eur. J Neurol. 2012;19:458-807.

13. Cisse A, Souare IS, Larkhis S, Cisse B, Beavogui K, Morel Y, et al. Atypical neurosyphilis: 28 cases observed at the University Hospital Center of Conakry. Med Trop Rev Corps Sante Colon. 2002;62:150-4.

14. Rubin AN, Espiridion ED, Truong NH, Lofgren DH. Neurosyphilis present anxiety: a case report. Cureus. 2018;10:3020

15. Sethi S, Das A, Kakkar N, Banga SS, Prabhakar S, Sharma M. Neurosyphilis in a tertiary care hospital in north India. Indian J Med Res. 2005;122:249-53.

16. Berger JR, Dean D. Neurologic aspects of systemic disease. In: José B, José F, editors. Handbook of Clinical Neurology Part III. Elsevier (1613); 2014;121:1461-72.

17. O'Donnell JA, Emery CL. Neurosyphilis: a current review. Curr Infect Dis Rep. 2005;7:277-84.

18. Chahine LM, Khoriaty RN, Tomford WJ, Hussain MS. The changing face of neurosyphilis. Int J Stroke. 2011;6:136-43.

19. Sharma C, Nath K, Kumawat BL, Khandelwal D, Jain D. Erb's paraplegia with primary optic atrophy: unusual presentation of neurosyphilis: case report and review of literature. Ann Indian Acad Neurol. 2014;17:231-3.

20. Berger JR. Neurosyphilis and the spinal cord: then and now. J Nerv Ment Dis. 2011;199:912-3.

21. Nayak S, Acharjya B. VDRL test and its interpretation. Indian $\mathrm{J}$ Dermatol. 2012;57:3-8.

22. Marra CM. Update on neurosyphilis. Curr Infect Dis Rep. 2009;11:127-34.

23. Marra CM, Maxwell CL, Dunaway SB, Sahi SK, Tantalo LC. Cerebrospinal fluid treponema pallidum particle agglutination assay for neurosyphilis diagnosis. J Clin Microbiol. 2017;55:1865-70.

24. Marra CM, Maxwell CL, Smith SL, Lukehart SA, Rompalo $\mathrm{AM}$, Eaton $\mathrm{M}$, et al. Cerebrospinal fluid abnormalities in patients with syphilis: association with clinical and laboratory features. J Infect Dis. 2004;189:369-76. 
25. Tashiro K, Moriwaka F, Sudo K, Akino M, Abe H. Syphilitic myelitis with its magnetic resonance imaging (MRI) verification and successful treatment. Jpn J Psychiatry Neurol. 1987;41:269-71.

26. Kikuchi S, Shinpo K, Niino M, Tashiro K. Subacute syphilitic meningomyelitis with characteristic spinal MRI findings. J Neurol. 2003;250:106-7.
27. Nabatame H, Nakamura K, Matuda M, Fujimoto N, Dodo Y, Imura T. MRI of syphilitic myelitis. Neuroradiology. 1992;34:105-6.

28. Shen WC, Lee SK, Ho YJ, Lee KR, Mak SC, Chi CS. MRI of sequela of transverse myelitis. Pedia Radiol. 1992;22:382-3.

29. Bulundwe KK, Myburgh CJ, Gledhill RF. Syringomyelia complicating syphilitic spinal meningitis: a case report. Eur J Neurol. 2000;7:231-6. 